\title{
A sneak peep at adenoid /acantholytic variant of oral squamous cell carcinoma
}

\author{
Ketki Kalele ${ }^{1, *}$, Rahul Deshmukh², Atul Alsi ${ }^{3}$ \\ ${ }^{\mathbf{1}}$ Assistant Professor, Dept. of Oral and Maxillofacial Pathology, V.Y.W.S. Dental College \& Hospital, Amravati, Maharashtra, \\ ${ }^{2}$ Dental Surgeon, ${ }^{3}$ Professor and HOD, Dept. of Dental, Dr. Panjabrao Deshmukh Memorial Medical College, Amravati, \\ Maharashtra, India
}

\section{*Corresponding Author: Ketki Kalele}

Email: drketkikalele@gmail.com

\section{Introduction}

Oral squamous cell carcinoma (OSCC) as known to all is the most common intraoral malignancy affecting the Asian population. As the pathologists encounter this malignancy most often it becomes easier to diagnose this neoplasm most of the times. But at times, it does not show typical features of conventional OSCC but shows some variations in its patterns. This makes the diagnosis of this neoplasm tricky one and also it changes the prognosis of the lesion. There are many variants of OSCC which includes Verrucous carcinoma, Basaloid OSCC, Acantholytic/Adenoid OSCC, Papillary OSCC, Spindle cell OSCC, Clear cell OSCC and Signet cell OSCC. ${ }^{1}$ Not much is known about all these variants of OSCC as very few cases are reported in our literature; but these variants certainly warrants attention as these can cause misdiagnosis of the malignancy and also the biological behavior and prognosis of the particular variant is different from conventional squamous cell carcinoma.

The present short review emphasizes on the must knows of one such variant which is Acantholytic/ Adenoid OSCC.

Acantholytic/Adenoid OSCC's are reportedly very rare variant of OSCC accounting for only $2-4 \%$ of the cases. ${ }^{2}$ However, there may be a possibility of higher percentage of occurrence of these variant cases which are left unreported. Adenoid OSCC is a histologically distinct entity as defined by WHO which is characterized by pseudoglandular pattern (adenoid pattern) produced by acantholysis of cells. ${ }^{3}$ Adenoid OSSC is usually known to occur on the sun exposed skin especially in cases of elderly male around sixth decade. ${ }^{4}$

Most of the cases in the head and neck region are found on the lip whereas; intra oral cases are still rare. ${ }^{3,4}$

\section{Pathogenesis}

Histologically, in this variant of OSCC there occurs acantholysis and degeneration within the islands of OSCC cells. Thus, there is appearance of duct like spaces with central empty lumen or sometimes lumen with acantholytic cells.

The detailed issue to be addressed here is why do acantholysis take place in this particular variant. In an article written by O'shea et $\mathrm{al}^{3}{ }^{3}$ they have given the molecular pathogenesis for the same which is elaborated in the following chart-

\section{Chart 1}

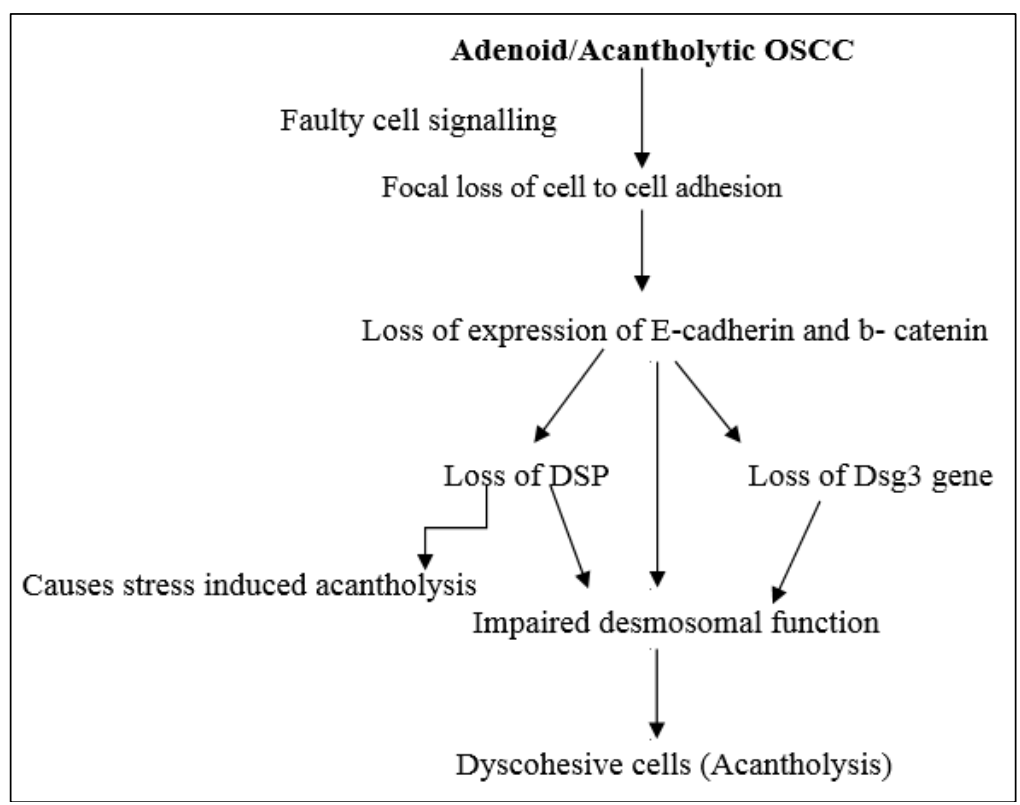


The above chart, gives the clear idea that acantholysis is the result of loss of desmosomal proteins amongst the cells.

\section{Histopathology}

Adenoid variant of OSCC not to mention is the histological variant of OSCC hence it is manadatory that there has to be areas of conventional squamous cell carcinomas in the section. These are typically seen to be well differentiated tumor. Alongwith those, there is a peculiar histopathological pattern of cells which include proliferation of cells, islands or solid growth pattern, occasionally with central keratinized pearls (Fig. 1). There is presence of dyscohesive cells in the tumor section.

The main histopathologic feature of this variant of tumor is presence of tubular or pseudoglandular structures containing acantholytic epithelial cells, islands or solid growth patterns which may show occasional keratin pearl formation. Acantholytic cells many times show dyskeratosis with dense eosinophilic cytoplasm (Fig. 2).

Tumor cells of this particular variant are known to have high nuclear to cytoplasmic $(\mathrm{N}: \mathrm{C})$ ratio. Nuclei varied from hyperchromatic \& more or less enlarged to large and/or multinucleated nuclei with open and fine chromatin. Along with these presence of mitotic figures were also very much common this variant. Another very interesting feature that is observed in the tumor is the presence of areas containing necrotic debris.

Some tumors showed dispersed large cells containing large amounts of deeply staining (eosinophilic) cytoplasm with peripheral vesicular nucleus which mimicks a high grade sarcoma. Hence it is essential to establish proper diagnostic criteria as adenoid OSCC can get misdiagnosed with many other sarcomas. ${ }^{4,5}$

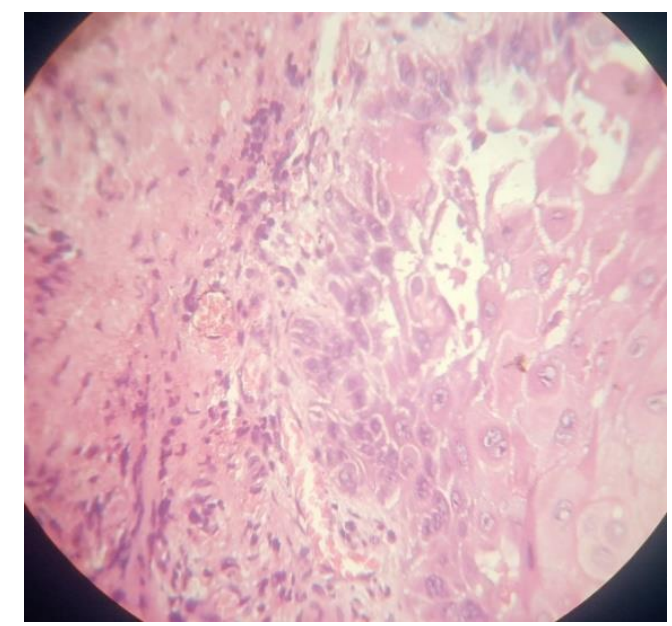

Fig. 1: $40 \mathrm{X}$ view of the section showing acantholytic cells with dark eosinophilic cytoplasm

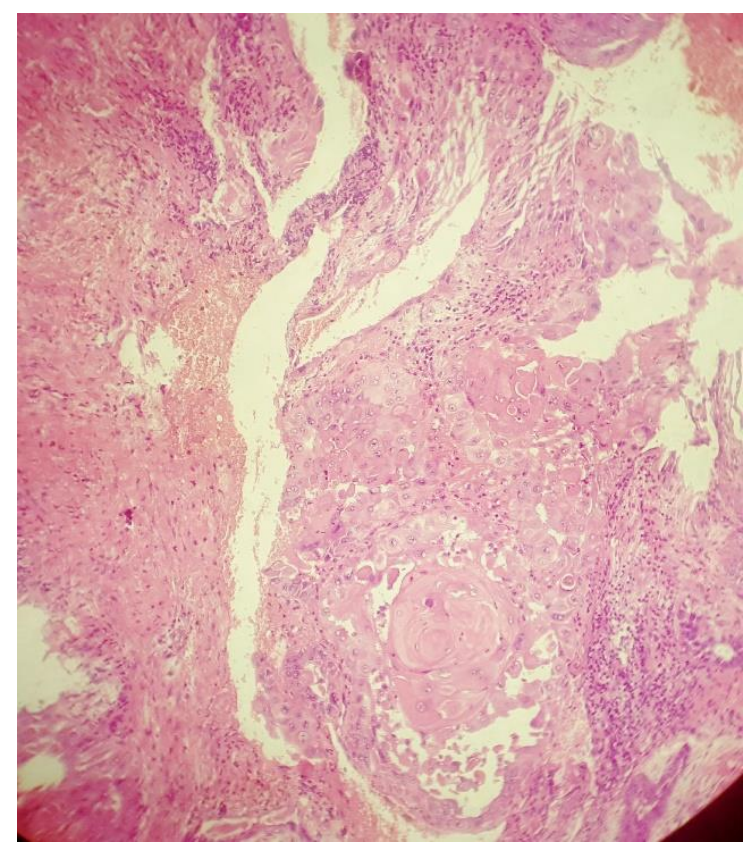

Fig. 2: $10 \mathrm{X}$ view of acantholytic squamous cell carcinoma with central keratin pearl and dyscohesive cells in the lumen of a malignant island

\section{Diagnostic Criteria for Diagnosing Adenoid OSCC}

1. Basic cell should be of keratinizing squamous type.

2. Adenoid structure consisting of a rounded space with definite wall, principally of one cell thickness.

3. Lumen of the adenoid/ ductular structure containing single or group of dyskeratotic acantholytic cells.

4. Hyperkeratosis ${ }^{5}$

\section{Histopathological Differential Diagnosis}

As a variant in histomorpholigical form Adenoid OSCC has various histological mimicks which produce diagnostic dilemmas and often misdiagnosis that further cause improper diagnostic, prognostic and treatment related mishaps. There are many tumors which show similar features as that of the adenoid OSCC but the following table illustrates the most common tumors which mimicks adenoid OSCC. . $^{2,-6}$ 
Table 1

\begin{tabular}{|c|c|c|}
\hline Adenosquamous carcinoma & Mucoepidermoid carcinoma & Angiosarcoma \\
\hline $\begin{array}{l}\text { Production of mucous in } \\
\text { adenosquamous carcinoma } \\
\text { differentiates it from non mucous } \\
\text { producing adenoid OSCC }\end{array}$ & $\begin{array}{l}\text { Presence of intermediate cells, } \\
\text { mucous cells as well as } \\
\text { mucous } \\
\text { differentiates it from adenoid } \\
\text { OSCC }\end{array}$ & $\begin{array}{l}\text { This is one of the toughest differential } \\
\text { diagnoses as the pseudovascular } \\
\text { spaces show close resemblance in } \\
\text { both the tumors. } \\
\text { The presence of area of conventional } \\
\text { squamous cell carcinoma adenoid } \\
\text { OSCC gives the clue for its diagnosis } \\
\text { which is absent in angiosarcoma. } \\
\text { Positivity to IHC markers CD34 \& } \\
\text { CD31 denotes angiosarcoma }\end{array}$ \\
\hline
\end{tabular}

\section{Clinical Relevance/Prognosis}

Apart from diagnostic challenge that this tumor poses it also differs in biologic behavior and has different prognosis then conventional type. Intraoral tumors showing acantholytic changes are found to be more aggressive with overall poor prognosis. Hence, once diagnosed it should be clearly conveyed to the clinicians and the clinicians should opt for a multidisciplinary approach to treat this tumor and should also keep close follow up. ${ }^{2,4}$

The unfavorable prognosis could be attributed to cellular acantholysis which is possibly a risk factor for metastasis of the malignant cells. Along with desmosomal protein dysfunction there is also dysregulation of laminin-5 which acts as tumor biological indicator of the unfavorable prognosis of Adenoid OSCC. ${ }^{3}$

\section{Conclusion}

To conclude, it is clear that adenoid OSCC although not very commonly encountered, still needs attention as these acantholytic tumors show loss of proteins which cause progression and metastasis of tumor.

\section{References}

1. Pathak J, Swain N, Patel S, Poonja L. Histopathological variants of oral squamous cell carcinoma-institutional case reports. Journal of Oral and Maxillofacial Pathology. JOMFP. 2014;18(1):143-145.

2. Chandrakala J, Srinath S, Giraddi GB, Kendole RK. Adenoid Squamous Cell Carcinoma of Oral Cavity: a Case Report. J Dent Shiraz Univ Med Sci. 2018;19(1):6873.

3. O'Shea C, Fitzpatrick J E, and. Koch P J. Desmosomal defects in acantholytic squamous cell carcinomas. $J$ Cutan Pathol. 2014;41(11):873-879.

4. Mardi K and Singh N. Acantholytic squamous cell carcinoma of the oral cavity: A rare entity. J Oral Maxillofac Pathol. 2014;18(1):S128-S130.

5. SAJIN M, PRISĂCARU A H, LUCHIAN M C. Acantholytic squamous cell carcinoma: pathological study of nine cases with review of literature. Rom J Morphol Embryol. 2014;55(2):279-283.
6. Driemel O, Richter U M, Hakim S G et al. Oral acantholytic squamous cell carcinoma shares clinical and histological features with angiosarcoma. Head \& Face Medicine 2008; 4(17):1-6. 